TECHNICAL NOTE

\title{
THE VARIATION IN UNDRAINED SHEAR CHARACTERISTICS DURING CONSOLIDATION PROCESS
}

\author{
Takeshi Kamei ${ }^{i}$, Shoji Ogawa $^{\text {ii) }}$ and Nobuyuki Tanaka ${ }^{i i i)}$
}

\begin{abstract}
In order to investigate a quantitative approach to the shear strength gained due to a consolidation process within a 24 hours period and to check the validity of a $3 \mathrm{t}$ method for the closing of the consolidation period (JSSMFE, 1979), a set of undrained triaxial tests was performed on a cohesive soil. It was found that the process of increase in undrained shear strength consists of primary and secondary processes, and that the $3 \mathrm{t}$ method for the closing of the consolidation period in laboratory tests (JSSMFE, 1979), is a useful method for determining undrained shear strength. The $2 \mathrm{t}$ method, however, may be used when the shortening of the consolidation period is required.
\end{abstract}

Key words : cohesive soil, consolidated undrained shear, pore pressure, secondary compression, shear strength, stress path, stress-strain curve, test procedure, time effect, triaxial compression test (IGC : D 6)

\section{INTRODUCTION}

It has been well known that the undrained shear strength of clays increases with an increase in cosolidation period. The influence of consolidation period on the stressstrain characteristics of the clay has been reported by many researchers. Bjerrum and Lo (1963) pointed out that the shear characteristics of clay were dependent upon the age of the sample, and with time the clay became more brittle with smaller failure strain and the undrained shear strength showed a slight increase. They explained these results by the growing of cohesive bonds at the contact points between the particles. These bonds lead to a greater resistance against deformation, however, it was gradually destroyed by increasing strain. Bjerrum (1967) also explained that the reduction of water content during delayed consolidation led to a more stable configuration

i) Research Associate, Deparment of Civil Engineering, The Technological University of Nagaoka, Kamitomioka, Nagaoka, Niigata.

ii) Professor, ditto.

iii) Officer, Osaka Prefectural Office, Higashi-ku, Osaka. Manuscript was received for review on July 24, 1986.

Written discussions on this note should be submitted before April 1, 1988, to the Japanese Society of Soil Mechanics and Foundation Engineering, Sugayama Bldg. 4G, Kanada Awaji-cho 2-23, Chiyoda-ku, Tokyo 101, Japan. Upon request the closing date may be extended one month. 
of the structure, thus developing increased strength. A similar result of this sort of study was reported by Whitman (1960). The increase in pore pressure in specimens subjected to undrained shear for various periods after consolidation has also been investigated (Walker, $1969 \mathrm{a}, 1969 \mathrm{~b}$ ).

Mikasa et al. (1971) investigated the influence of consolidation period on shear strength of remoulded clays by using direct shear apparatus. In the experiment, they reported that the shear strength of clay increases with anlogarithum of the consolidation periods. Shen et al. (1973) stated that secondary compression would cause an increase in undrained strength and a yield stiffer stressstrain characteristics for a clay. Yasuhara and Ue (1983) proposed a method for estimating the amount of increase in undrained shear strength of clay due to secondary compression, i. e., the increase in strength to be a power function of the elapsed time during secondary compression, including three parameters which can be obtained from oedometer tests and triaxial compression tests.

The Japanese Society of Soil Mechanics and Foundation Engineering (1979), on the other hand, recommended the $3 \mathrm{t}$ method based on the $\log t$ method for the closing of consolidation period in laboratory tests. The reduction in consolidation period is one of the main merits in using laboratory tests.

In spite of the above-mentioned studies, however, there has not been enough understanding of the undrained shear characteristics during consolidation process especially near the point of the end of primary consolidation. In construction works on soft clays, the steploading method is of ten employed to increase soil strength. In some cases, however, it is difficult to determine the consolidation period for each steps. Because such consolidation period may be determined from the settlement-time relationship without considering the distribution of soil strength in the ground. It is very important to understand, therefore, the gain in shear strength of the soil under consolidation in engineering sight. In addition, it is desir-
Table 1. Index properties of soil sample

\begin{tabular}{c|c}
\hline Soil sample & Yoneyama clay \\
\hline$G_{s}$ & 2.82 \\
$w_{L}(\%)$ & 64.2 \\
$w_{p}(\%)$ & 36.6 \\
$I_{p}$ & 27.6 \\
Sand $(\%)$ & 42.5 \\
Silt $(\%)$ & 29.5 \\
Clay $(\%)$ & 28.0
\end{tabular}

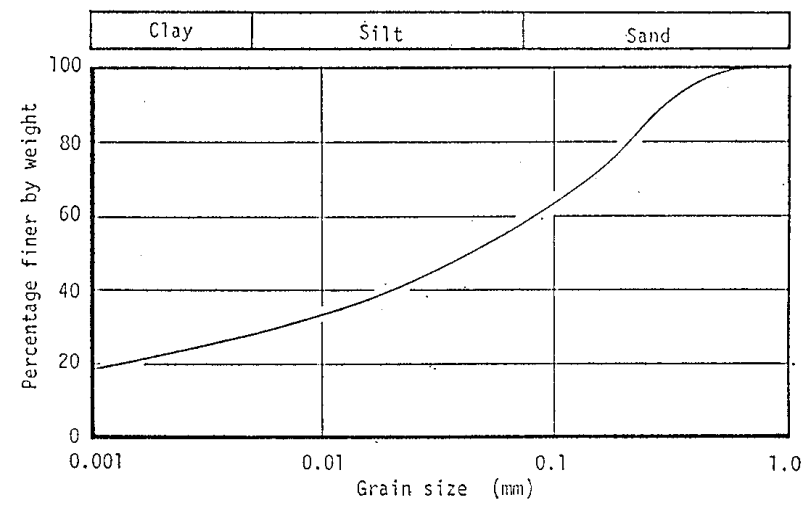

Fig. 1. Grain size distribution curve of the sample

able to short the date of construction based on the study in economy sight. The purpose of this paper is to investigate a quantitative approach to the gain in shear strength due to consolidation process within a 24 hours period and to check the validity of the $3 \mathrm{t}$ method for the closing of the consolidation period from shear strength point of view.

\section{EXPERIMENTS}

Sample

Yoneyama red clay was used in the experiments described in this paper. Dredged Yoneyama red clay was thoroughly remoulded by adding distilled water, put through a 840 $\mu \mathrm{m}$ sieve. Index properties of the soil sample is summarized in Table 1. Fig. 1 shows the grading curve of the soil sample. It is noted that the Yoneyama clay has a high diffusion ability as expected from the grading curve. Test specimen for triaxial tests was prepared as follows. The soil sample was puddled at a water content of approximately 1.3 times the liquid limit in a soil mixer for 
about an hour, then put into a preconsolidation cell. Preconsolidation was performed one-dimensionally under a vertical pressure of $68.6 \mathrm{kPa}$. After completion of consolidation, the consolidated soil block was taken out of the cell and cut into twelve pieces, and the test specimen for triaxial tests was trimmed from each soil pieces. The test specimen prepared through these procedures may be considered fully saturated. Size of the test specimen was $50 \mathrm{~mm}$ in diameter and $125 \mathrm{~mm}$ in height.

\section{Triaxial Tests}

A series of consolidated undrained triaxial compression tests was performed on the soil sample. In the compression tests, specimens are consolidated isotropically or under $K_{0}$ condition to a given consolidation period and then subjected to undrained compression by increasing axial pressure, lateral pressure being kept constant during compression process. These triaxial tests are denoted as $\overline{\mathrm{CIUC}}$ and $\overline{\mathrm{CK}_{0} \mathrm{UC}}$ tests, respectively.

Two different values of vertical effective consolidation pressure $156 \mathrm{kPa}$ and $196 \mathrm{kPa}$ were used in the consolidation process. A back pressure of $98 \mathrm{kPa}$ was applied to all the test specimens throughout the consolidation and shear processes.

Although the complicated phenomena were produced in the specimen by stop being consolidation, the specimens failed at the centre of specimen, where can be considered as the point of the most delayed dissipation of excess pore pressure.

As mentioned above, most of the previous studies on the consolidation period of the soil specimen had adopted more than a day because their studies aimed at the increase in undrained shear strength due to secondary compression. Fig. 2(a) shows the $3 \mathrm{t}$ method which has been recommended by JSSMFE (1979) as a practical method. One can arrive at the closing of the appropriate consolidation period $t_{E}$ by means of this figure by following the steps listed below:

i) The time $t_{T}$ is defined as the intersection of the steepest gradient line of the
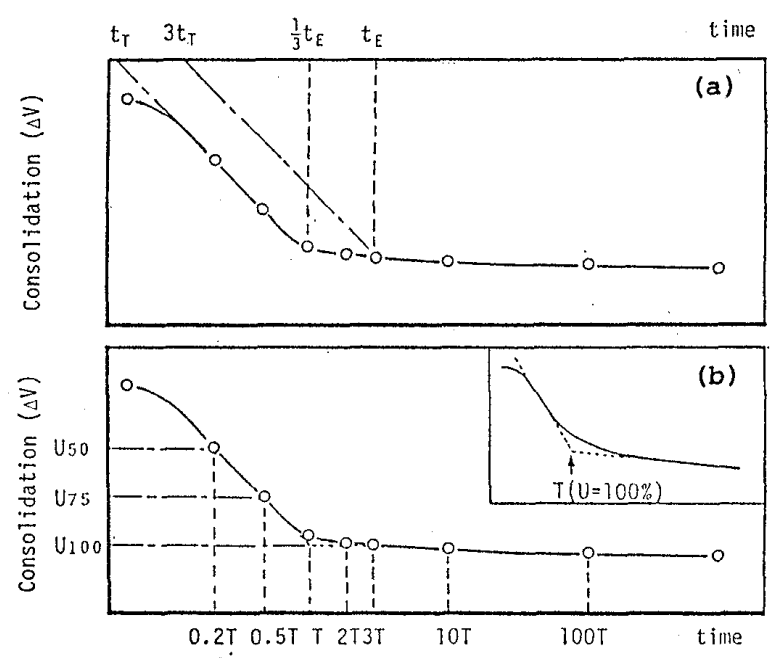

Fig. 2. The $3 \mathrm{t}$ method for the closing of consolidation period (JSSMFE) and the point $T$ of $100 \%$ primary compression

volume change-time curve and the horizontal line on semi-logarithum graph paper.

ii) The time $t_{E}$ is defined as the intersection of the experimental curve and the shifted line should be parallel to the steepest gradient line where the amount of shifting is three times of $t_{T}$ on semi-logarithum graph paper.

Fig. 2(b) shows the intersection of the two corresponding tangents suggested by Casagrande to determine the point $T$ of $100 \%$ primary compression.

Eight different consolidation periods within a 24 hours were employed in this study, i.e., $0.2 T, 0.5 T, T, 2 T, 3 T, 10 T, 100 T$ and 24 hours. The $T$ and $t_{E} / 3(U=100 \%)$ point and its time in this soil sample show fairly good agreement as shown in Fig. 2. For the time, $0.2 T$ and $0.5 T$, corresponding to the time for $U=50 \%$ and $U=90 \%$ were observed, respectively. The distribution of excess pore pressure at the ending of consolidation would be in the shape of parabola. Although the excess pore pressure values were checked by the two pore pressure transducers at the top and bottom platens, the specimens were maintained for about four hours for the distribution of excess pore pressure to become a quadrangle. The portions of the top and end near the point of platen were in the overcon- 
solidated area where they might have dissipated away easily during the consolidation, the failure plane occurred at the centre of specimen which is considered as the weakest area. To be exact, although the distribution of shear strength in the specimen is different, it may be possible to estimate the undrained shear strength of the clay gained due to a consolidation process qualitatively.

Pore pressure coefficient $B$ in the present series of specimens was found practically equal to unity, the smallest value being 0.99 .

Shear tests were carried out with a constant rate of axial strain of $0.2 \% / \mathrm{min}$ (JSSMFE, 1979). For each test conditions, two to four tests were carried out. The repeatability of the test results was satisfactorily.

\section{TEST RESULTS AND DISCUSSIONS}

\section{Stress-Strain Characteristics}

Figs. 3 and 4 show typical stress-strain curves for the different periods of consolida-

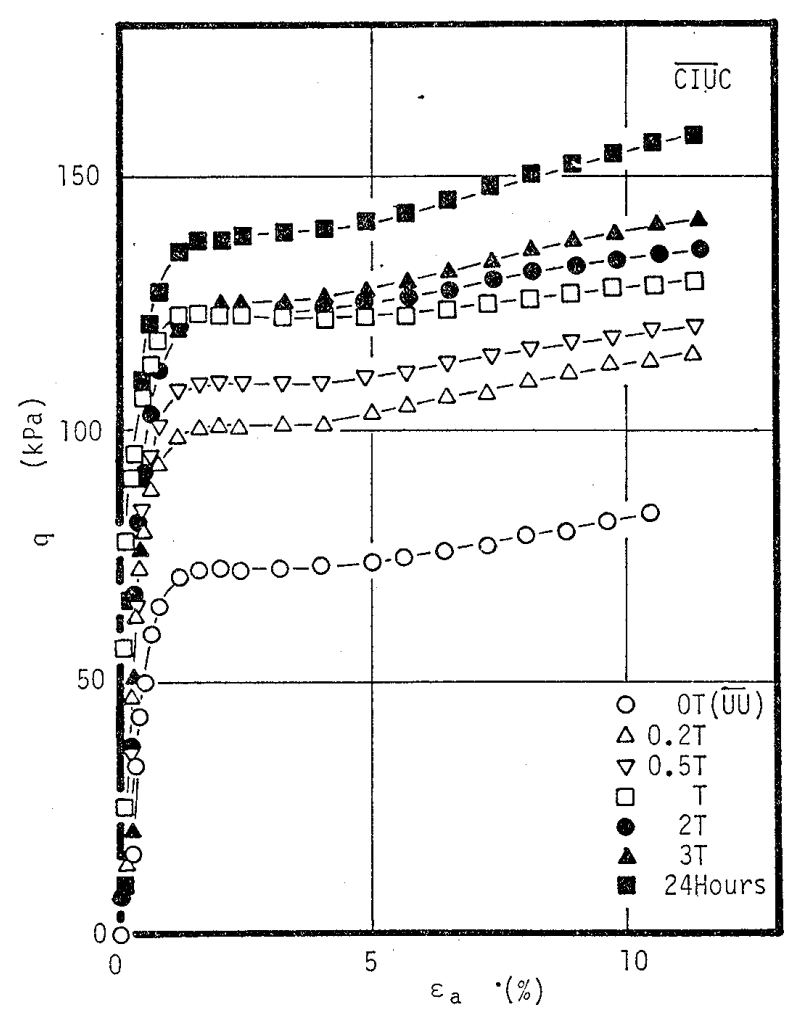

Fig. 3. Typical stress-strain curves for the different periods of consolidation in the $\overline{\text { CIUC test }}$ tion in the $\overline{\mathrm{CIU}} \mathrm{C}$ and $\overline{\mathrm{CK}_{0} \mathrm{UC}}$ tests respectively, where the principal stress difference $q=\sigma_{a}$ $-\sigma_{r}$ was used.

It will be seen in these figures that the maximum principal stress difference in the compression tests increases with a proceed in the consolidation periods. In addition, the shapes of stress-strain curves seem to be similar for each consolidation conditions. As seen in Fig. 4, the stress-strain curves of the $\overline{\mathrm{CK}_{0} \mathrm{UC}}$ tests have a pronounced peak, the peak stress is observed at $\varepsilon_{a}$ of about $0.25 \%$ irrespective of the consolidation periods. This result can be seen in elsewhere (Nakase and Kamei, 1983 and 1986).

\section{Excess Pore Pressure-Strain Characteristics}

Figs. 5 and 6 show typical excess pore pressure-strain curves for the different periods of consolidation in the $\overline{\mathrm{CIUC}}$ and $\overline{\mathrm{CK}_{0} \mathrm{UC}}$ tests respectively, where the excess pore pressure is denoted as $\Delta u$. It can be seen that the amount of exess pore pressure build up decreases with an increasing period of consolidation. In all the cases, the excess pore pressure builds up rapidly at the begin-

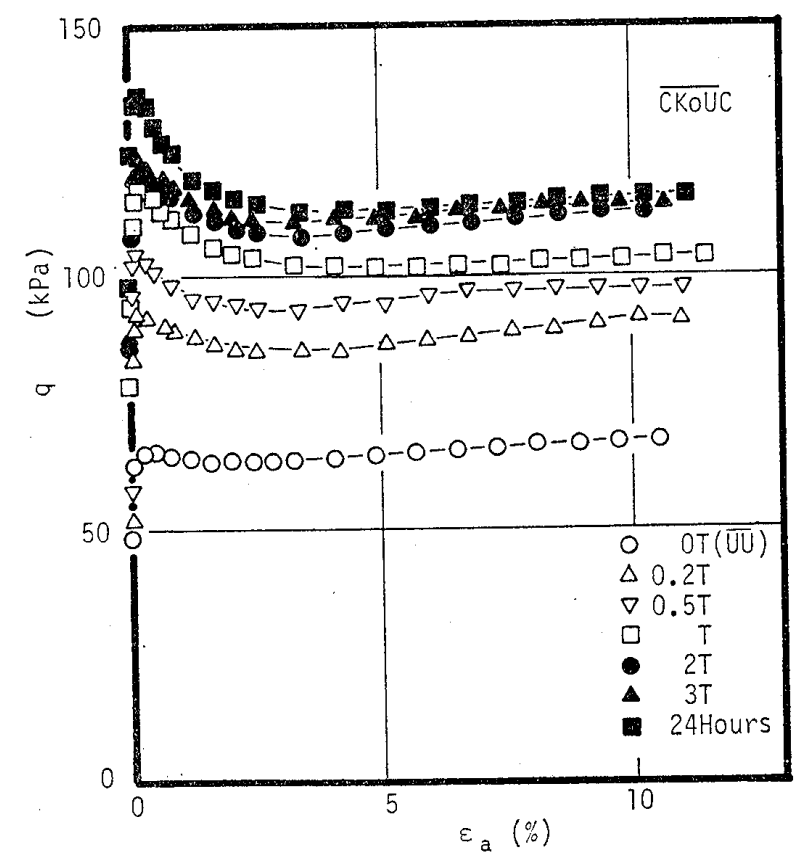

Fig. 4. Typical stress-strain curves for the different periods of consolidation in the $\overline{\mathrm{CK}_{0} \mathrm{UC}}$ test 


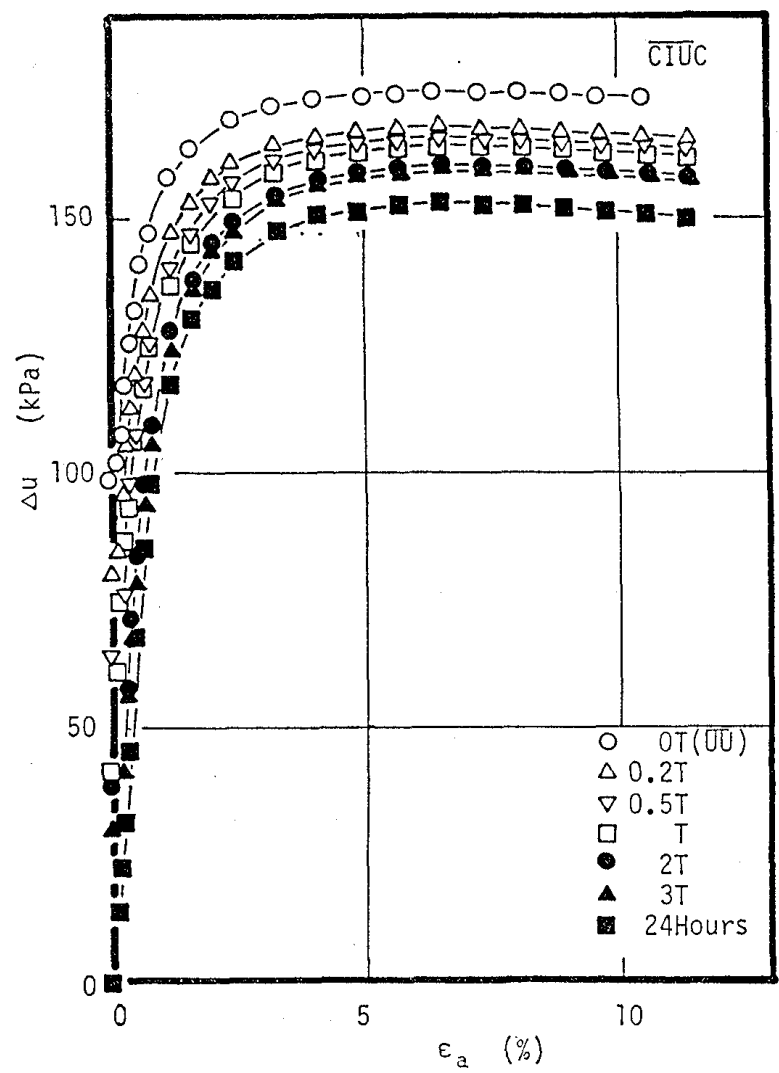

Fig. 5. Typical excess pore pressure-strain curves for the different periods of consolidation in the $\overline{\text { CIU }} \mathrm{C}$ test

ning of shear and then the rate decreases with an increase in strain and the maximum excess pore pressure is observed at $\varepsilon_{a}$ about $4 \%$ for all the specimens.

\section{Effective Stress Paths}

Typical effective stress paths for different periods of consolidation in the $\overline{\mathrm{CIU} C}$ and $\overline{\mathrm{CK}_{0} \mathrm{UC}}$ tests are shown in Figs. 7 and 8 respectively, where the principal stress difference $q, \sigma_{a}-\sigma_{r}$, and the mean effective stress $p^{\prime},\left(\sigma_{a}{ }^{\prime}+2 \sigma_{r}{ }^{\prime}\right) / 3$, are defined. As shown in these figures, the shapes of effective stress paths seem to be similar. The shapes of effective stress paths grow larger by the mean effective stress increases with increase in consolidation period. These stress paths are also characterized by their sharp reversal as they approach the critical state line, and thereafter they tend to proceed along the critical state line.

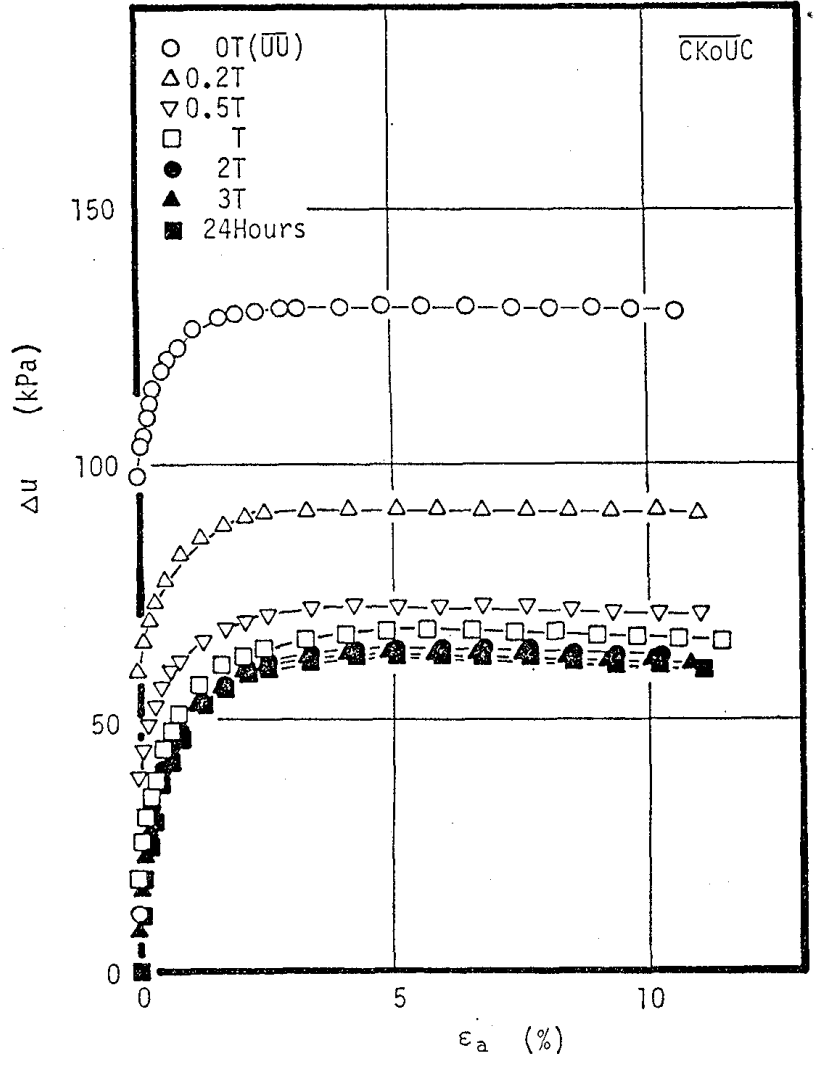

Fig. 6. Typical excess pore pressure-strain curves for the different periods of consolidation in the $\overline{\mathrm{CK}_{0} \mathrm{U}} \mathrm{C}$ test

Summary of the Triaxial Test Results

Triaxial test results obtained in the present experiments are summarized in Table 2 . In

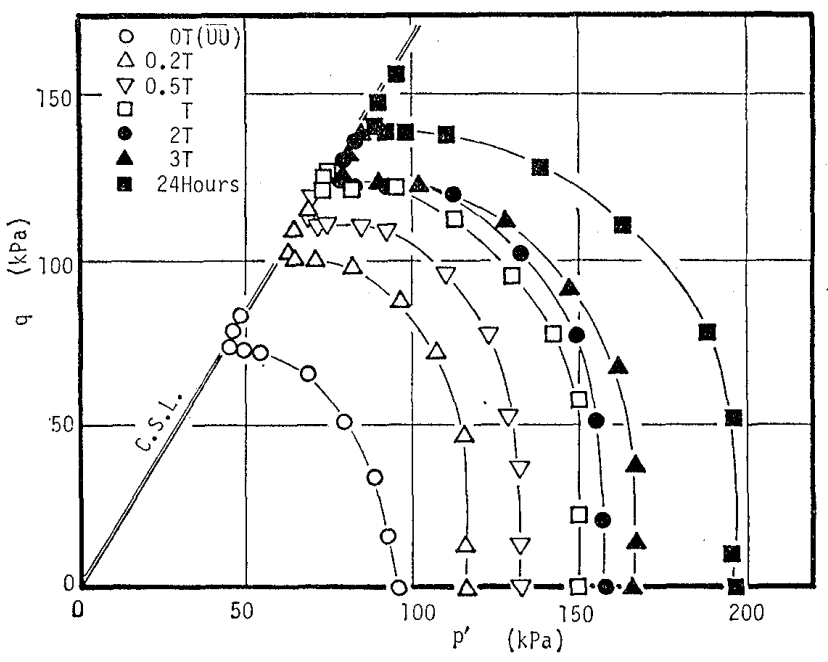

Fig. 7. Typical effective stress paths for the different periods of consolidation in the $\overline{\mathrm{CIU}} \mathrm{C}$ test 


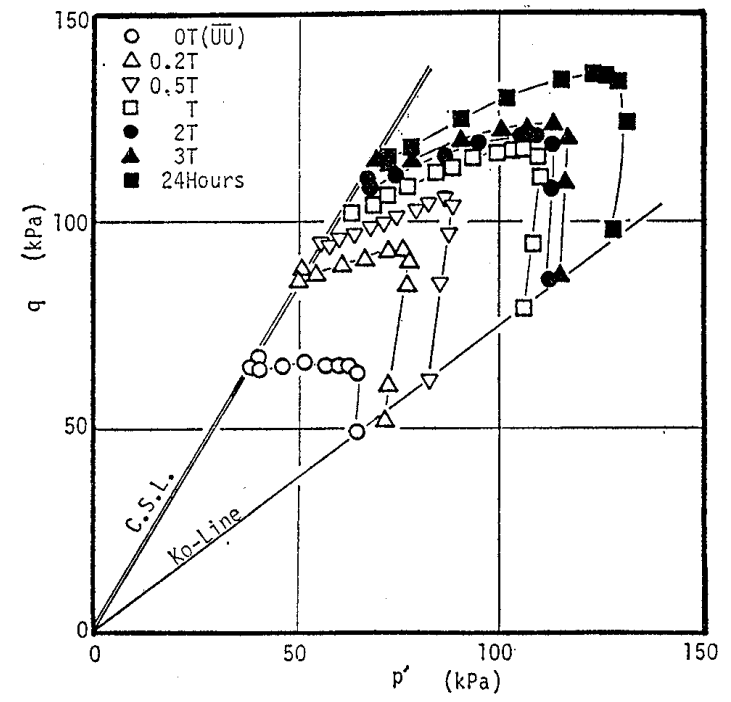

Fig. 8. Typical effective stress paths for the different periods of consolidation in the $\overline{\mathrm{CK}_{0} \mathrm{UC}}$ test

Table 2. Summary of triaxial test results

\begin{tabular}{|c|c|c|c|c|c|c|}
\hline $\begin{array}{l}\text { Consolidation } \\
\text { Time }\end{array}$ & Test Type & $c_{u} / p$ & $\begin{array}{c}\varepsilon f \\
(\%)\end{array}$ & $A_{f}$ & $\phi^{\prime}\left({ }^{\circ}\right)$ & $K_{0}$ \\
\hline \multirow[t]{2}{*}{$O T(\mathrm{UU})$} & $\overline{\text { CIUTC }}$ & 0.376 & 4.19 & 0.95 & 35.3 & 1.00 \\
\hline & $\overline{\mathrm{CK}} \overline{\mathrm{K}}_{0} \mathrm{UC}$ & 0.330 & 0.19 & 0.52 & 34.9 & 0.50 \\
\hline \multirow{2}{*}{$0.2 T(U=50 \%)$} & $\overline{\mathrm{CIUC}}$ & 0.263 & 4.06 & 0.80 & 36.3 & 1.00 \\
\hline & $\overline{\mathrm{CK}_{0} \mathrm{UC}}$ & 0.252 & 0.15 & 0.23 & 35.5 & 0.54 \\
\hline \multirow[t]{2}{*}{$0.5 T(U=75 \%)$} & C̈IUC & 0.281 & 4.07 & 0.89 & 36.3 & 1.00 \\
\hline & $\overline{\mathrm{CK}_{0} \mathrm{UC}}$ & 0.276 & 0.20 & 0.23 & 37.3 & 0.50 \\
\hline \multirow[t]{2}{*}{$T$} & CIUC & 0.310 & 4.13 & 0.97 & 37.2 & 1.00 \\
\hline & $\overline{\mathrm{CK}_{0} \mathrm{UC}}$ & 0.301 & 0.22 & 0.41 & 37.0 & 0.50 \\
\hline \multirow[t]{2}{*}{$2 T$} & $\overline{\text { CIUC }}$ & 0.321 & 4.11 & 0.95 & 36.4 & 1.00 \\
\hline & $\overline{\mathrm{CK}_{0} \mathrm{UC}}$ & 0.308 & 0.22 & 0.47 & 36.5 & 0.49 \\
\hline \multirow[t]{2}{*}{$3 T$} & $\overline{\text { CIUC }}$ & 0.325 & 4.95 & 0.99 & 37.2 & 1.00 \\
\hline & $\overline{\mathrm{CK}_{0} \mathrm{UC}}$ & 0.318 & 0.19 & 0.44 & 36.9 & 0.49 \\
\hline \multirow[t]{2}{*}{$10 T$} & $\overline{\text { CIUC }}$ & 0.330 & 4.90 & 1.03 & 36.1 & 1.00 \\
\hline & $\overline{\mathrm{CK}_{0} \mathrm{UC}}$ & 0.320 & 0.17 & 0.39 & 36.4 & 0.50 \\
\hline \multirow[t]{2}{*}{$100 T$} & $\overline{\text { CIUC }}$ & 0.339 & 4.90 & 1.07 & 35.9 & 1.00 \\
\hline & $\overline{\mathrm{CK}_{0} \mathrm{UC}}$ & 0.326 & 0.18 & 0.49 & 36.6 & 0.50 \\
\hline \multirow[t]{2}{*}{24 Hours } & CĨUC & 0.357 & 4.15 & 1.06 & 36.4 & 1.00 \\
\hline & $\overline{\mathrm{CK}_{0} \mathrm{UC}}$ & 0.350 & 0.17 & 0.52 & 36.7 & 0.50 \\
\hline
\end{tabular}

the table, the angle of shearing resistance $\phi^{\prime}$ was determined at the condition of $\left(\sigma_{1}{ }^{\prime}\right)$ $\left.\sigma_{3}{ }^{\prime}\right)_{\max }$, but all other parameters such as $A_{f}$ and $\varepsilon_{f}$ were values corresponding to the condition $\left(\sigma_{1}-\sigma_{3}\right)_{\max }$, since the main topic of the present paper was the undrained shear strength. As seen in the table, the different consolidation periods of the specimens have practically no effect on the effective-stress failure envelope of clay, i. e., the angle of

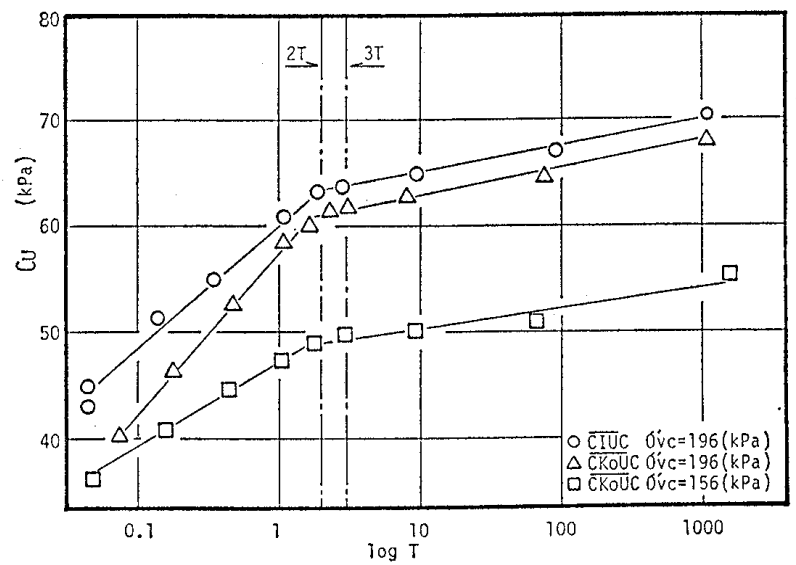

Fig. 9. The variation in undrained shear strength with the different consolidation periods

shearing resistance of $36.4^{\circ}$ was obtained irrespective of the different consolidation periods and consolidation conditions.

\section{The Variation in Undrained Shear Strength with the Different Consolidation Periods}

The variation in undrained shear strength with the different consolidation periods was plotted on semi-logarithum graph paper in Fig. 9. As seen in the figure, the undrained shear strength shows the bilinear relationship irrespective of consolidation conditions. The intersection point of two straight lines extrapolated from the initial and final portions of the curve is situated at the point of $2 T$. Judging from this result, the process of increase in undrained shear strength consists of primary and secondary processes as was the case with consolidation process of clay. The primary process can be considered that the void ratio decreases with an increasing of the mean effective stress. The secondary process, by contrast, can be considered that the void ratio decreases while mean effective stress is constant, i. e., secondary compression. At this stage, the consolidation period $3 \mathrm{t}$ method is situated at the point of secondary part in undrained shear strength diagram. As above mentioned, the $3 \mathrm{t}$ method is a useful method for determining undrained shear strength and it has been a conservative evaluation in the sight of undrained shear strength. Alternately, the $2 \mathrm{t}$ method may 


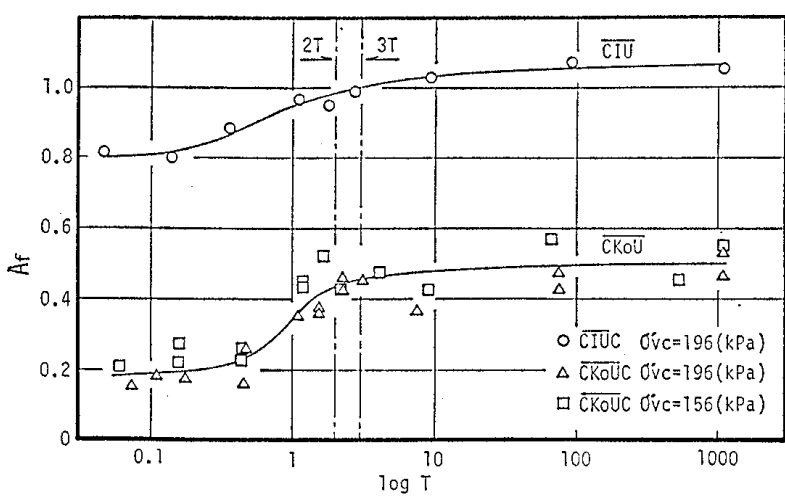

Fig. 10. The variation in pore pressure coefficient at failure $A_{f}$ with the different consolidation periods

be recommended when the shortening of the consolidation period is required.

Pore Pressure Coefficient A (Skempton, 1954)

The pore pressure coefficient at failure $A_{f}$ obtained in the present experiment is plotted against consolidation periods in Fig. 10. Larger values of $A_{f}$ in the isotropically consolidated specimens as compared with that in the $K_{0}$-consolidated specimens was observed. When the consolidation period lies between $0.5 T$ and $2 T$ there is a 'trasitional' part of the values irrespective of consolidation conditions, the values are constant at the conditions of less than consolidation period 0.5 $T$ and more than consolidation period $2 T$ is stable irrespective of consolidation conditions.

\section{CONCLUSIONS}

The variation in undrained shear characteristics during consolidation process was investigated by a set of undrained triaxial tests. The following conclusions were obtained:

1) The process of increase in undrained shear strength consists of primary and secondary processes.

2) The $3 \mathrm{t}$ method for the closing of the consolidation period in laboratory tests (JSSMFE, 1979) is a useful method for determining undrained shear strength. The $2 t$ method, however, may be used when the shortening of the consolidation period is re- quired.

\section{NOTATION}

$A_{f}=$ pore pressure coefficient at failure

$c_{u}=$ undrained shear strength

$\overline{\mathrm{CIU}} \mathrm{C}=$ isotropically consolidated undrained compression test

$\overline{\mathrm{CK}_{0} \mathrm{UC}}=K_{0}$-consolidated undrained compression test

$K_{0}=$ coefficient of earth pressure at rest

$p^{\prime}=$ mean effective stress, $\left(\sigma_{a}{ }^{\prime}+2 \sigma_{r}{ }^{\prime}\right) / 3$

$q=$ principal stress difference, $\sigma_{a}-\sigma_{r}$

$t_{T}=$ the intersection of the steepest gradient line of the volume change-time curve and the horizontal line on semilogarithum graph paper

$t_{E}=$ the intersection of the volume changetime curve and the shifted line should be parallel to the steepest gradient line where the amount of shifting is three times of $t_{T}$ on semi-logarithum graph paper.

$T=$ the point of $100 \%$ primary compression of the specimen

$\Delta u=$ excess pore pressure

$\varepsilon_{a}=$ axial strain

$\varepsilon_{f}=$ axial strain at failure

$\phi^{\prime}=$ angle of shear resistance $\left(\sigma_{1}{ }^{\prime} / \sigma_{3}{ }^{\prime}\right)_{\max }$ was taken as the failure conditions

\section{REFERENCES}

1) Bjerrum, L. and Lo, K.Y. (1963): "Effect of aging on the shear-strength properties of a normally consolidated clay," Geotechnique, Vol. 8, No. 2, pp. 147-157.

2) Bjerrum, L. (1967) : "Engineering geology of Norwegian normally consolidated marine clays as related to settlements of buildings," Geotechnique, Vol.17, No.2, pp.81-118.

3) Berre, T. and Bjerrum, L. (1973): "Shear strength of normally consolidated clays, "Proc. 8 th ICSMFE, Vol. 1-1, pp. 39-49.

4) Mikasa, M., Kinoshita, T. and Takada, N. (1971): "Relationship between undrained shear strength and consolidation period on cohesive soils," Proc. 6 th Research Meeting of JSSMFE, pp. 137-140 (in Japanese).

5) Nakase, A. and Kamei, T. (1983): "Undrained shear strength anisotropy of normally consolidated cohesive soils," Soils and Foundations, Vol. 23, No. 1, pp. 91-101. 
6) Nakase, A. and Kamei, T. (1986): "Influence of strain rate on undrained shear characteristics of $K_{0}$-consolidated cohesive soils," Soils and Foundations, Vol.26, No.1, pp. 85-95.

7) Shen, C. K., Arulanandan, K. and Smith, W.S. (1973): "Secondary consolidation and strength of a clay," Proc. ASCE, Vol.99, No.SM 1, pp. 95-110.

8) Skempton, A.W. (1954): "The pore-pressure coefficients A and B," Geotechnique, Vol.4, pp. 143-147.

9) The Japanese Society of Soil Mechanics and Foundation Engineering (1979): Soil Testing Manual, p. 516 .

10) Walker, L. K. (1969) : "Secondary consolidation in the shear strength of clays," Proc. ASCE, Vol. 95, No. SM 1, pp. 167-188.

11) Walker, L. K. (1969) : "Undrained creep in a sensitive clay," Geotechnique, Vol. 19, No.4, pp. 515-539.

12) Whitman, R. V. (1960): "Some considerations and data regarding the shear strength of clays," Proc. ASCE, Research Conference on Shear Strength of Cohesive Soils, Boulder, Colorado, pp. 581-614.

13) Yasuhara, K. and Ue, S. (1983): "Increase in undrained shear strength due to secondary compression," Soils and Foundations, Vol.23, No. 3 , pp. 50-64. 